Case Reports
in Dermatology
Case Rep Dermatol 2021;13:36-41

DOI: $10.1159 / 000510736$

Published online: January 25, 2021 (c) 2021 The Author(s)

Published by S. Karger AG, Basel www.karger.com/cde

This article is licensed under the Creative Commons Attribution-NonCommercial 4.0 International License (CC BY-NC) (http://www.karger.com/Services/OpenAccessLicense). Usage and distribution for commercial purposes requires written permission.

\title{
Vitiligo-Like Depigmentation following Treatment with Imiquimod 5\% Cream for Condylomata Acuminata
}

\author{
Maram Alatabani ${ }^{a} \quad$ Yasser Ghobara $^{\mathrm{b}} \quad$ Ahmed Alissa $^{\mathrm{b}}$ \\ aDepartment of Dermatology, Armed Forces Hospital, Khamis Mushait, Saudi Arabia; \\ ${ }^{b}$ Department of Dermatology, Derma Clinics, Riyadh, Saudi Arabia
}

\section{Keywords}

Imiquimod · Vitiligo · Hypopigmentation - Depigmentation · Pigmentation disorders ·

Condylomata acuminata

\begin{abstract}
Imiquimod cream is an immunomodulatory agent that has been approved by the US Food and Drug Administration for use in the treatment of anogenital warts (condylomata acuminata) due to its local immune effects in activating Toll-like receptors 7 and 8 on antigen-presenting cells, resulting in reduction of the viral load of human papillomavirus with subsequent wart regression. After its application, some side effects are commonly reported, including erythema, edema, scaling, erosion, and ulceration. While pigmentary changes, including vitiligo-like depigmentation, have been mentioned as a possible side effect, they have rarely been reported in the literature. Alterations in pigmentation occur because imiquimod application causes human melanocyte apoptosis and autodestruction resulting in loss of melanocytes. Herein, we report the rare case of a 34-year-old healthy male who developed vitiligo-like depigmentation following imiquimod application for his genital warts. This case report aims to increase physicians' awareness of this possible side effect that could be irreversible and difficult for the patient to accept.




\section{Case Reports in Dermatology}

Case Rep Dermatol 2021;13:36-41

DOI: $10.1159 / 000510736$

(c) 2021 The Author(s). Published by S. Karger AG, Basel www.karger.com/cde

Alatabani et al.: Imiquimod-Induced Depigmentation

\section{Introduction}

Imiquimod $\left(\right.$ Aldara $\left.^{\circledR}\right)(2.5,3.75$, and $5 \%)$ is a commercially available topical cream. It is currently approved by the US Food and Drug Administration (FDA) for use as a topical treatment for biopsy-confirmed small superficial basal cell carcinoma measuring up to $2 \mathrm{~cm}$ in its greatest diameter over the neck, trunk, or extremities (excluding the hands and feet) [1], nonhyperkeratotic nonhypertrophic actinic keratoses over the face and/or scalp [2,3], and external genital and perianal warts (condylomata acuminata) in adults $[4,5]$. In condylomata acuminata, which is considered to be a sexually transmitted disease, it is approved to be used as a $5 \%$ cream three times weekly for up to 16 weeks, or as a $3.75 \%$ cream daily for up to 8 weeks [6]. Its topical application is known to effect both innate and adaptive immune responses. Therefore, it will result in antiviral, antitumor (due to its antiangiogenic effect) [7], and immunoregulatory properties [6]. As a mechanism of action, the application of imiquimod will result in Toll-like receptor 7 (TLR7) and Toll-like receptor 8 (TLR8) activation [8, 9] on antigen-presenting cells. Activation of TLR7 leads to interactions between the cytoplasmic portion of the receptor and MyD88. Therefore, it facilitates the association of MyD88 with interleukin-1 receptor-associated kinase, which, in turn, activates TNF, tumor necrosis factor (TNF) receptorassociated factor 6. Eventually, this results in the stimulation of nuclear factor-кB-mediated signaling. Thus, imiquimod promotes antigen-presenting cell maturation leading to the secretion of cytokines, mainly IFN- $\alpha$, IL-12, and IL-18, which will result in IFN- $\gamma$ secretion via naïve T cells. IFN- $\gamma$ will enhance cell-mediated immunity via the Thelper 1 (TH1) response [6], resulting in a reduction of the viral load of human papillomavirus type 6 and 11, which are frequently detected in condylomata acuminata, with subsequent wart regression and normalization of keratinocyte proliferation without evidence of scarring [10].

Regarding adverse reactions, erythema, edema, scaling, erosion, and ulceration at the imiquimod application site have been shown to be the most common side effects [6]. Those adverse effects have been reported to increase more as the amount and frequency of use of imiquimod increases, and they are more often seen in patients with photodamaged skin, i.e., actinic damage [6]. Although pigmentary alteration has been mentioned as a possible side effect of imiquimod, it has been rarely reported in the literature. It was first reported by Brown et al. in 2005 [11]. This side effect might be linked to continuous use of imiquimod after the onset of irritant contact dermatitis, which is known to be the most common side effect of that cream [12].

There are some reported cases regarding this side effect. For example, at Shanghai Dermatology Hospital (China), during the period ranging from January 2014 to December 2015, around 6 cases of vitiligo-like depigmentation following the use of imiquimod were reported. All of the cases involved male patients, ranging in age from 27 to 59 years, who were all given imiquimod 5\% cream to treat condylomata acuminata. After around 6-15 weeks, they started to notice some hypopigmentation in their genital area [12]. Three other cases of vitiligo-like depigmentation in the treatment area were reported at Seoul National University Hospital (Korea) in people who used imiquimod $5 \%$ for almost 3 months to treat extramammary Paget's disease [9]. Moreover, a 61-year-old male, diagnosed with superficial basal cell carcinoma at the Royal Brisbane Hospital (Australia), was reported to have vitiligo-like depigmentation over the treated area after using imiquimod 5\% for five nights per week for almost 13 weeks [13]. Finally, a 25-year-old Caucasian female with no personal or family history of vitiligo was followed up at Ospedale Maggiore Policlinico di Milano Hospital (Italy) with mul-

\section{Karger'=}




\section{Case Reports in Dermatology}

Case Rep Dermatol 2021;13:36-41

DOI: $10.1159 / 000510736$

(c) 2021 The Author(s). Published by S. Karger AG, Basel www.karger.com/cde

Alatabani et al.: Imiquimod-Induced Depigmentation

tiple genital warts involving the vulvar area; she developed genital depigmentation following the use of imiquimod 5\% cream three times weekly for 18 months [5].

\section{Case Presentation}

A 34-year-old single male, with no known medical conditions, presented to our clinic with multiple smooth surfaced hyperpigmented pedunculated lesions over both sides of his scrotum and a few small verrucous papules over the dorsal surface of his penis. He was diagnosed as having genital warts (condylomata acuminata) and was prescribed imiquimod $5 \%$ cream with clear instructions to carefully apply it over the affected area three times per week. He was clearly instructed and directed to apply a thin layer of the cream over a clean area and to rub it in until it was no longer visible, before going to sleep for at least $8 \mathrm{~h}$, and to then wash it off in the morning.

Three months later that young healthy male, who was not known to have any personal or family history of vitiligo, presented with vitiligo-like depigmentation (Fig. 1-3). The depigmentation was extending beyond the application sites, but it was still localized to his genital area. Other vitiligo-prone areas were not involved. The patient denied using any topical treatment other than imiquimod.

Physical examination showed multiple well-defined depigmented macules and patches localized over his genital area (specifically: the scrotal area, the glans penis, and the shaft of the penis), which showed accentuation of pigment loss with Wood's lamp examination. Unfortunately our patient refused to have a biopsy of the depigmented areas to confirm his diagnosis histopathologically.

During follow-up, we advised the patient to discontinue imiquimod immediately, and he was given topical tacrolimus $0.03 \%$ twice daily instead. One month later the vitiligo patches started to improve slightly, but then no further improvement occurred and the lesions remained unchanged. This, in turn, had a negative impact on the patient in terms of satisfaction and compliance.

\section{Discussion and Conclusion}

In the literature, imiquimod application has been reported to cause depigmentation via different mechanisms of action, including postinflammatory depigmentation, necrosis or apoptosis of melanocytes, and immune-mediated vitiligo-like reactions [5]. One reason for the presence of those depigmented lesions after topical imiquimod application is that the cream could induce local melanocyte apoptosis [12], which was observed by TUNEL assay, by Hoechst 33258 staining, and by measuring mitochondrial membrane potential in melanocytes [8]. Another explanation is that when imiquimod binds to TLR7, activation of the TH1 pathway occurs as previously mentioned, due to stimulation of specific cytokines, such as INF- $\alpha$, IL-12, and IL-18, which cause its activation and enhancement. TH1 pathway activation will result in predominantly cytotoxic CD8+ T cell infiltrates, which play a critical role in the onset and progress of vitiligo [14] due to melanocyte destruction [13].

Furthermore, imiquimod will increase IFN- $\alpha$, TNF- $\alpha$, and IL-12 secretion, which is known to play a role in causing vitiligo-like depigmentation and contributing to vitiligo pathogenesis as well [15]. Imiquimod will also downregulate the enzyme tyrosinase, which is important in

\section{Karger'=}




\section{Case Reports in Dermatology}

Case Rep Dermatol 2021;13:36-41

DOI: $10.1159 / 000510736$

(c) 2021 The Author(s). Published by S. Karger AG, Basel www.karger.com/cde

Alatabani et al.: Imiquimod-Induced Depigmentation

melanin biosynthesis, and MITF gene expression (a master gene that regulates melanogenesis, melanocyte differentiation, and survival) in melanocytes [15]. Moreover, the application of imiquimod increases the level of nitric oxide and can lead to autodestruction of melanocytes [13]. Finally, topical imiquimod application is also known to increase Langerhans cell activity, which can increase melanocyte destruction due to cytotoxic $\mathrm{T}$ cell activation [13].

In conclusion, imiquimod $5 \%$ cream is considered to be a safe medication and has been approved by the FDA for treating a number of dermatological diseases such as superficial basal cell carcinoma, actinic keratoses, and condylomata acuminata. It has commonly known side effects that occur frequently, such as erythema, edema, scaling, erosion, and ulceration at the application site. However, in our case, we reported a rare side effect of that medication: vitiligo-like depigmentation over the application site. We report this case to increase physicians' awareness of this potential and possibly irreversible side effect, which could be difficult for the patient to accept. For this reason, such adverse effects should be discussed with the patient before prescribing imiquimod. If the cream is used, it should be done so under close observation and it should be discontinued as soon as this side effect is noticed.

\section{Statement of Ethics}

Written informed consent was obtained from the patient for any information or images regarding this case to be published. The research was conducted ethically in accordance with the World Medical Association Declaration of Helsinki.

\section{Conflict of Interest Statement}

The authors have no conflicts of interest to declare.

\section{Funding Sources}

None.

\section{Author Contributions}

All authors meet the International Committee of Medical Journal Editors criteria for authorship, and they contributed equally to this work and gave approval for publication of the final version of the manuscript.

\section{References}

1 Ceilley RI, Del Rosso JQ. Current modalities and new advances in the treatment of basal cell carcinoma. Int J Dermatol. 2006 May;45(5):489-98.

2 Hadley G, Derry S, Moore RA. Imiquimod for actinic keratosis: systematic review and meta-analysis. J Invest Dermatol. 2006 Jun;126(6):1251-5.

\section{Karger'=}




\section{Case Reports in Dermatology}

Case Rep Dermatol 2021;13:36-41

DOI: $10.1159 / 000510736$

(c) 2021 The Author(s). Published by S. Karger AG, Basel www.karger.com/cde

Alatabani et al.: Imiquimod-Induced Depigmentation

3 Swanson N, Abramovits W, Berman B, Kulp J, Rigel DS, Levy S. Imiquimod 2.5\% and 3.75\% for the treatment of actinic keratoses: results of two placebo-controlled studies of daily application to the face and balding scalp for two 2-week cycles. J Am Acad Dermatol. 2010 Apr;62(4):582-90.

4 Workowski KA, Berman SM. Centers for Disease Control and Prevention sexually transmitted diseases treatment guidelines. Clin Infect Dis. 2007 Apr;44(Suppl 3):S73-6.

5 Serra MC, Menicanti C, Pennacchioli E, Tosti G. Vulvar vitiligo-like depigmentation and multiple halos of hypomelanosis at the trunk following treatment with imiquimod $5 \%$ cream for vulvar condylomata: casual or related events? An Bras Dermatol. 2014 Sep-Oct;89(5):806-7.

6 Fox M, Helfrich Y, Kang S. Other topical medications. In: Bolognia JL, Schaffer JV, Cerroni L, editors. Dermatology. 4th ed. Philadelphia: Elsevier Health Sciences; 2018. p. 2269-77.

7 Costa A, Bonner M, Arbiser J. Antiangiogenic Agents. In: Kang S, Amagai M, Bruckner A, Enk A, Margolis D, McMichael A, et al., editors. Fitzpatrick's dermatology. Volume 2. 9th ed. New York, NY: McGraw-Hill Education LLC; 2018. p. 3594

8 Li W, Xin H, Ge L, Song H, Cao W. Induction of vitiligo after imiquimod treatment of condylomata acuminata. BMC Infect Dis. 2014 Jun;14(1):329.

9 Kwon $\mathrm{HH}$, Cho KH. Induction of vitiligo-like hypopigmentation after imiquimod treatment of extramammary Paget's Disease. Ann Dermatol. 2012 Nov;24(4):482-4.

10 Tyring SK, Arany I, Stanley MA, Stoler MH, Tomai MA, Miller RL, et al. Mechanism of action of imiquimod 5\% cream in the treatment of anogenital warts. Prim Care Update Ob Gyns. 1998 Jul;5(4):151-2.

11 Brown T, Zirvi M, Cotsarelis G, Gelfand JM. Vitiligo-like hypopigmentation associated with imiquimod treatment of genital warts. J Am Acad Dermatol. 2005 Apr;52(4):715-6.

12 Long FQ, Zhao LS, Qian YH. Vitiligo or vitiligo-like hypopigmentation associated with imiquimod treatment of condyloma acuminatum: not a causal event. Chin Med J (Engl). 2017 Feb;130(4):503-4.

13 Sriprakash K, Godbolt A. Vitiligo-like depigmentation induced by imiquimod treatment of superficial basal cell carcinoma. Australas J Dermatol. 2009 Aug;50(3):211-3.

14 Ezzedine K, Harris J. Vitiligo. In: Kang S, Amagai M, Bruckner A, Enk A, Margolis D, McMichael A, et al., editors. Fitzpatrick's dermatology. Volume 1. 9th ed. New York, NY: McGraw-Hill Education LLC; 2018. p. $1330-50$.

15 Mori S, Akasaka T. Imiquimod-induced vitiligo-like hypopigmentation after treatment for radiation keratosis. Clin Exp Dermatol. 2016 Dec;41(8):930-2.

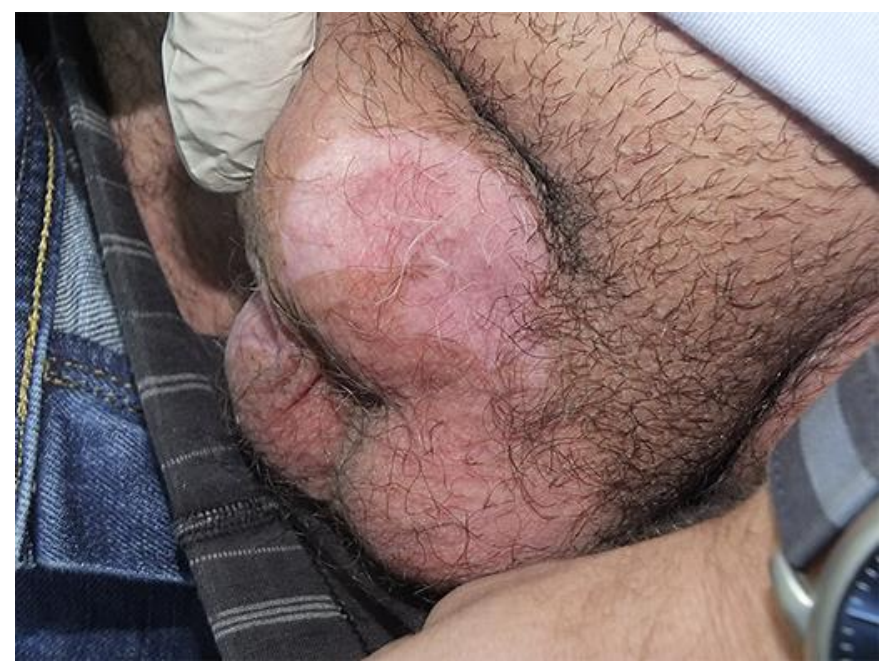

Fig. 1. Single well-defined sharply depigmented patch localized over the left scrotal area.

\section{Karger'=}




\section{Case Reports in Dermatology}

\begin{tabular}{l|l}
\hline Case Rep Dermatol 2021;13:36-41 \\
\hline DOI: 10.1159/000510736 & $\begin{array}{l}\text { C 2021 The Author(s). Published by S. Karger AG, Basel } \\
\text { www.karger.com/cde }\end{array}$ \\
\hline
\end{tabular}

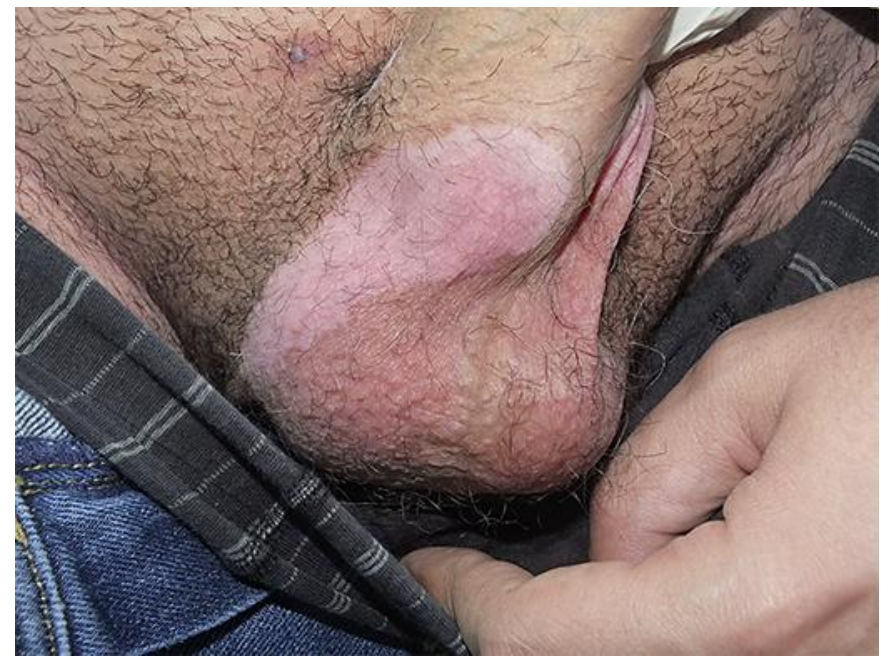

Fig. 2. Another depigmented nonscaly patch over the right scrotal area.

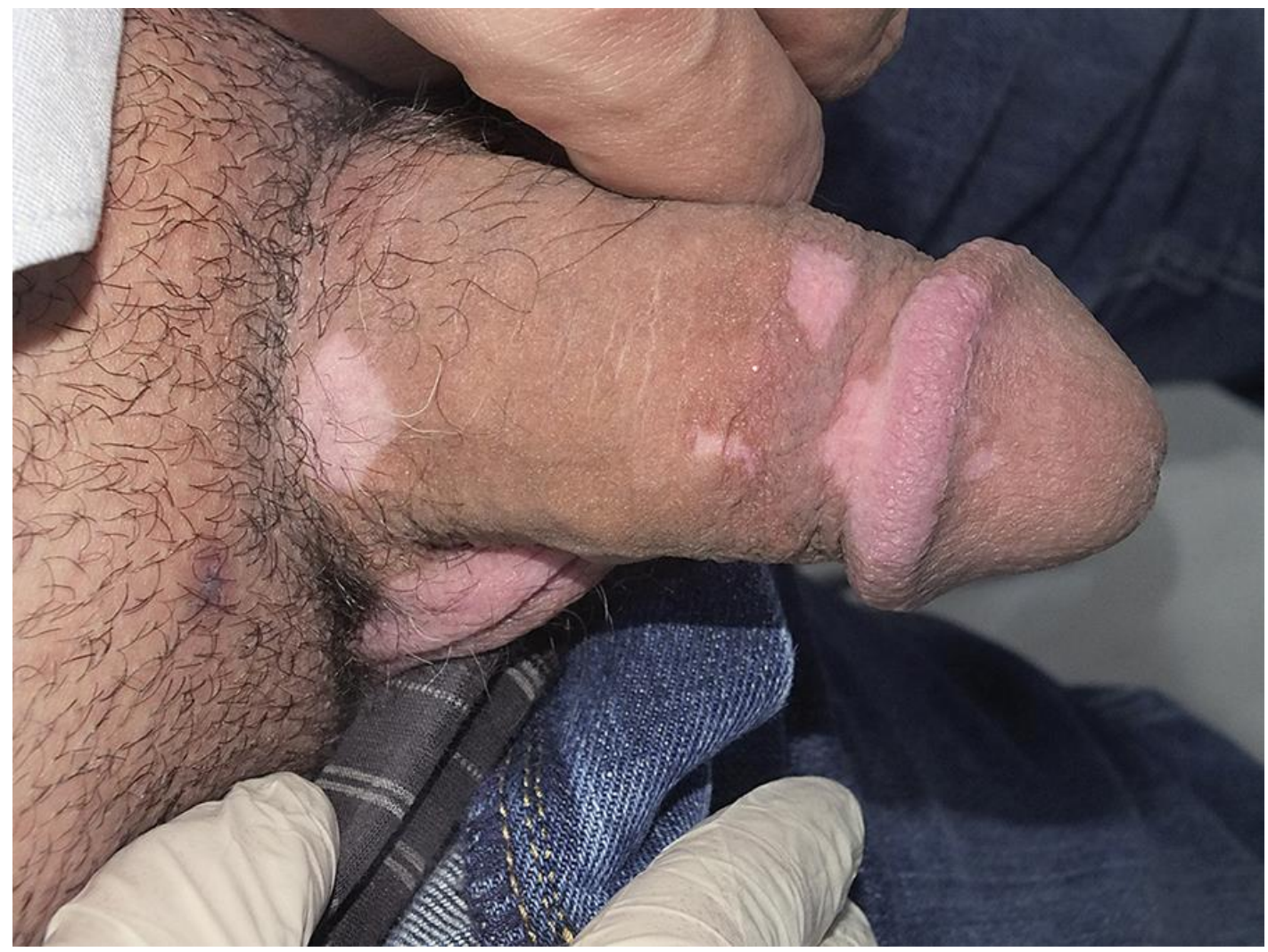

Fig. 3. Multiple depigmented macules and patches over the glans penis and the shaft of the penis.

\section{Karger'}

